\title{
Contrato de opção e fundo financeiro como instrumentos de gestão de risco climático na alocação de água \\ Option Agreement and Financial Fund as instruments of climate risk management in the allocation of water
}

\section{Augusto de Brito Sousa \\ Francisco de Assis de Souza Filho Samíria Maria Oliveira da Silva}

RESUMO: O conhecimento e o estudo de mecanismos financeiros associados à alocação de água são relevantes dado o seu potencial papel na adaptação à variabilidade e mudanças climáticas. Assim, este trabalho objetivou pesquisar e desenvolver mecanismos financeiros de gestáo do risco climático associado a garantias diferenciadas de uso que possibilite a compensação devido à transferência de risco entre usuários e um fundo de regularizaçáo que reduza variaçóes significativas dos preços da água em anos de escassez hídrica. Para construir os mecanismos proposto inicialmente definiu-se a vazáo disponível para alocação. Essa vazão foi distribuída entre os usuários por meio de dois métodos de alocaçáo: rateio linear e sistema de prioridade. Em seguida, analisaram-se os ganhos e as perdas dos usuários por meio de funçōes benefícios. Com base nesses valores formulou-se um contrato de opçáo entre os setores e um fundo de financeiro para guardar os recursos necessários para o pagamento das opções. $\mathrm{O}$ contrato de opçáo tem como base a retirada anual do sistema. Ele é uma possibilidade entre outras de promover transferências de risco e seria acionado em períodos secos e desligado em períodos úmidos. Os pagamentos de opçóes foram menores que os impactos da irrigação em todo o intervalo simulado. Além disso, as vantagens financeiras para o setor urbano superam as perdas a partir desse coeficiente.

PALAVRAS-CHAVE: compensação financeira, alocação, transferência hídrica.
Submetido: 06/11/2014

Revisão: 08/07/2015

Aprovado: 04/09/2015
ABSTRACT: The knowledge and study of financial mechanisms associated with water allocation are relevant because of their potential role in adaptation to climate variability and change. Thus, this study aimed to research and develop financial mechanisms for climate risk management that enable compensation for risk transfer between users and an adjustment fund that reduces significant variations in water prices in years of water scarcity. To build the mechanisms proposed initially flow available for allocation was defined. This flow was distributed among users via two allocation methods: Linear apportionment and priority system. Then user gains and losses were analyzed by benefit functions. Based on these values an option agreement between sectors was formulated as well as a financial fund to save resources necessary for the payment of options. The option agreement is based on the annual withdrawal system. This is one of the possibilities to promote risk transfers and it would be triggered during dry periods and turned off during wet periods. Options payments were lower than the irrigation impacts throughout the simulated range. Moreover, the financial benefits to the urban sector outweigh the losses from that coefficient.

KEYWORDS: financial compensation, insurance, water transfer.

\section{INTRODUÇÃO}

A crescente demanda por recursos hídricos reforça a motivação para melhorar o processo de alocação de água entre os usuários e os setores econômicos.

A disponibilidade hídrica para diversos fins é condicionada pela regra de operaçáo do sistema de reservatórios. Esta regra de operação frequentemente esta associada a determinado horizonte temporal (curto, médio e longo prazo) e estão condicionadas pelo comportamento que o tomador de decisão tem em relação ao risco imposto pela variabilidade climática e a incerteza sobre o futuro.

Em regióes que apresentam alta frequência de ocorrência de anos secos na série histórica de afluência, como no Nordeste Brasileiro, adota-se uma operação de reservatórios baseada em salvaguardas, isto é, prolonga-se a disponibilidade do recurso hídrico impondo racionamento a alguns usos antes do reservatório entrar em colapso. 
Em curto prazo essa regra pode ser eficiente, porém, em longo prazo leva a imposição de garantias diferenciadas entre os diversos usuários podendo aumentar significativamente as garantias do abastecimento urbano (considerado setor prioritário) com relação à garantia realizada no cálculo da outorga e reduzir drasticamente as garantias para os outros usos.

A regra de operaçáo descrita acima leva a ocorrência de transferência de risco entre usuários. Nesse sentido, faz-se necessário buscar alternativas para uma gestáo eficiente dos recursos hídricos de modo que a alocaçáo de água garanta o direito de uso adquirido pelos usuários e proporcione equidade ao sistema de recursos hídricos.

Brown e Carriquity (2007) propuseram a adoção de mecanismos financeiros para gerir os riscos em hidrossistemas visando transformar a variabilidade hidrológica em valores monetários de forma a possibilitar a garantia de renda à população na ocorrência de um evento hidrológico extremo.

Assim, o conhecimento e o estudo desses mecanismos são relevantes, dado o seu potencial papel na adaptação à variabilidade e mudanças climáticas. Além disso, o modelo jurídico-institucional de alocação pode se basear em um destes mecanismos ou em uma composição entre estes para definir como alocar seus recursos.

Este trabalho propóe-se a desenvolver um mecanismo financeiro associado a garantias diferenciadas de uso que possibilite a compensação devido à transferência de risco entre usuários e um fundo de regularização que reduza variaçóes significativas dos preços da água em anos de escassez hídrica.

\section{CONTRATO DE OPÇÃO}

A utilização de mecanismos financeiros na alocação de água possibilita recompensar os agentes sociais pelos riscos que eles foram expostos ou que decidiram expor-se. Essa recompensa não é realizada com a eliminação do risco, ao contrário, ocorre por intermédio da transferência dele.

Atualmente, na gestão de riscos climáticos tem-se utilizado três instrumentos de transferência de risco: i) os seguros tradicionais, ii) os seguros indexados e iii) os derivativos climáticos.

Os seguros tradicionais são aquelas construídas para proteger o agente social e econômico contra as perdas. Já o seguro indexado é projetado usando um índice (por exemplo, precipitação e vazão afluente) que serve como proxy para perdas, eliminando a necessidade de avaliar as perdas individuais (SKEES; COLLIER, 2008).

Os derivativos vêm sendo utilizados há muitos séculos, mas, só foram aplicados para proteção aos riscos climáticos no século final do século XX, entretanto, eles sempre estiveram disponíveis a poucas empresas e com altos custos. Dentre os derivativos existentes pode-se citar o contrato de opção.

Conforme Montano (2004), no mercado de opçóes, é negociado o direito de compra ou venda de um ativo numa data futura, por um preço pré-determinado. $\mathrm{O}$ titular da opção é quem compra o contrato e, com isso, adquire um direito. Já o participante que vende uma opção é conhecido como lançador e, ao fazê-lo, assume uma obrigação. Assim, ele permite que o seu detentor tenha um direito sobre algo, mas, diferentemente dos outros contratos, não o prende a nenhuma obrigação.

Assim com as opçóes, é possível executar diferentes estratégias para as mais diversas necessidades de hedge em vários tipos de mercado (CALIJURI, 2009). Um agricultor, por exemplo, agindo como hedger, estará sempre adquirindo opçóes de venda de sua produção pelas quais pagará o prêmio e exercerá o seu direito se o preço de exercício for superior ao preço do mercado físico. No caso do preço de exercício estar abaixo do preço da commodity no mercado físico à vista, o agricultor deixa de exercer seu direito e perde o valor do prêmio pago (ZAVAGLIA et al., 2011).

Segundo Brown e Carriquiry (2007), esse tipo de contrato também é usado como alternativa ao mercado de água para uma troca de uso d'água por uma compensação financeira em anos de seca. Nesse caso, os contratos seriam negociados a um preço ajustado e forneceriam uma confiança e credibilidade de uma troca quando necessária.

Com isso, a água permanece produtiva em todos os anos, diferentemente de algumas medidas de alocação de água que utilizam estratégias conservadoras para a operaçáo dos sistemas hídricos.

Para Characklis et al. (2006), o contrato de opção ano-seco pode fornecer a disponibilidade que, de outra forma, a infraestrutura instalada náo poderia ofertar. Dessa forma, os contratos de opção, bem como, os outros tipos de derivativos é uma forma de transferência de risco que tem a possibilidade de uma maior utilização à medida que seus conceitos são disseminados, tendo em vista que, conforme já discutido, fenômenos climáticos afetam um elevado número de setores. 


\section{METODOLOGIA}

Para construir os mecanismos proposto inicialmente definiu-se a vazão disponível para alocação. Essa vazão foi distribuída entre os usuários por meio de dois métodos de alocação: rateio linear e sistema de prioridade. Em seguida, analisaram-se os ganhos e as perdas dos usuários utilizando as funçóes benefícios de Souza Filho e Brown (2009). Com base nesses valores formulou-se um contrato de opção entre os setores e um fundo de financeiro para guardar os recursos necessários para o pagamento das opçóes.

O detalhamento desta metodologia está descrito na sequência do texto.

\section{Local de aplicação}

O reservatório Orós foi escolhido como área de estudo, pois, ele é o reservatório com a maior quantidade de dados consistentes disponíveis do estado do Ceará. Os dados de afluência deste reservatório estão disponíveis para o período de 1912 a 1996 somando 85 anos de registro.

Este açude está localizado na cidade de Orós aproximadamente a $450 \mathrm{~km}$ de Fortaleza, capital do estado, e teve sua construção concluída no ano de 1961. Pertence à Bacia do Alto Jaguaribe, barrando o Rio Jaguaribe próximo à cidade de Iguatu drenando uma área de cerca de $24.000 \mathrm{~km}^{2}$ e tendo uma capacidade máxima de armazenamento de $1.940 \mathrm{hm}^{3}$.

De acordo com a Lei de Recursos Hídricos do Estado do Ceará (CEARÁ, 2010), a água disponível para distribuição é de $90 \%$ do volume Q90. Com base em dados historicamente observados, este é um volume de $600 \mathrm{hm}^{3} /$ ano.

Segundo Araújo (1990), antes da construção do açude Castanhão, o açude Orós era o maior reservatório do Estado do Ceará em capacidade de acumulação de água e tinha como finalidades a perenização do rio Jaguaribe, a irrigaçáo do Médio e Baixo Jaguaribe, a piscicultura, culturas agrícolas de áreas de montante, o turismo e o abastecimento da Região Metropolitana de Fortaleza- RMF.

Desta forma, para este estudo, elaborou-se uma situação hipotética em que a demanda urbana da cidade de Fortaleza foi incluída como demanda do reservatório Orós. Com isso, a alocação de água no reservatório foi realizada entre os dois usuários, abastecimento urbano com um volume demandado de $180 \mathrm{hm}^{3} /$ ano e a irrigaçáo com uma demanda de $420 \mathrm{hm}^{3} /$ ano.

\section{Vazão disponível para alocação}

A vazão disponível para a alocação entre o abastecimento urbano e a irrigação foi determinada utilizando a estratégia de operação do reservatório com vazão zero (estratégia adotada no estado do Ceará).

No cenário de vazão zero, o sistema hídrico é simulado com vazóes afluentes zero (estado mais crítico para o sistema) no período de julho a dezembro (futuro conhecido de 6 meses).

A simulação foi realizada por meio do balanço de massa do reservatório, conforme pode ser visto na equação 1 :

$$
\mathrm{V}_{\mathrm{t}+1}=\mathrm{V}_{\mathrm{t}}+\mathrm{I}_{\mathrm{t}}-\mathrm{E}_{\mathrm{t}}^{*} \mathrm{~A}-\mathrm{R}_{\mathrm{t}}-\mathrm{S}_{\mathrm{t}}
$$

Em que I é a afluência, E é a evaporação, A é a área do espelho d'água, $\mathrm{S}$ é o vertimento (retirada de água não controlada), $\mathrm{t}$ é o mês e $\mathrm{R}_{\mathrm{t}}$ representa a retirada controlada.

Foram utilizados os dados de evaporação disponíveis no banco de dados das normais climatológicas do INMET considerando a cidade de Iguatu. Esses dados são observados em evaporímetros de pichê com distribuição mensal. Para representar a evaporação sobre o reservatório adotou-se um coeficiente de oitenta por cento (80\%) dos valores da variável evaporação média.

Os dados de afluência foram obtidos no relatório de regionalização de vazóes da UFC/COGERH (2013) para o período de 1912 a 2012. Neste relatório foi utilizado o modelo SMAP (Soil Moisture Accounting Procedure) para a calibração e geração de vazóes, com discretização temporal mensal.

Contudo, para avaliar a incerteza inerente ao comportamento aleatório das afluências utilizou-se uma série sintética de 1000 anos de afluência. Para isso fez-se o ajuste da série histórica de vazão a distribuição Gamma de dois parâmetros.

O ajuste dos dados foi realizado aplicando o inverso da função gama de dois parâmetros, conservando a média e desvio padrão da série histórica. A distribuição de probabilidade da função gama tipo II está descrita na equação 2 .

$$
f(x)=\left\{\begin{array}{c}
\frac{1}{\beta^{\alpha} \Gamma(\alpha)} x^{\alpha-1} e^{-\frac{x}{\beta}}, 0<x<\infty \\
0, \text { para outros valores de } x
\end{array}\right.
$$


Em que, $\alpha>0$ é o parâmetro de forma, $\beta>0$ o parâmetro de escala e x é a variável aleatória em estudo. $\mathrm{O}$ alfa e beta foram obtidos com base na estatística da série histórica de vazão conforme as expressôes 3 e 4:

$$
\begin{aligned}
& \alpha=\left(\frac{\mu}{\sigma}\right)^{2} \\
& \beta=\frac{\sigma^{2}}{\mu}
\end{aligned}
$$

Em que $\mu$ é a média da série histórica da vazão afluente e é o desvio padrão dessa mesma série.

\section{Alocação de uso}

A vazão disponível para alocação foi distribuída entre o abastecimento urbano e a irrigação por intermédio de dois métodos de alocação: rateio linear e sistema de prioridade.

O método de Prioridades caracteriza-se pela escolha prioritária de um setor em detrimento de outros setores. Neste caso, leva-se em consideração a lei estadual de recursos hídricos que expressa o seguinte como fundamento: “... em situações de escassez, o uso prioritário dos recursos hídricos é o consumo humano e a dessedentação de animais".

Desta forma, a prioridade legal é do setor urbano em detrimento da irrigação em épocas de escassez. Para este método tem - se as seguintes condiçóes:

$$
\begin{gathered}
1^{\mathrm{a}} \text { condição }-\mathrm{Q}_{\mathrm{u}, \mathrm{t}}=\operatorname{menor}\left(\mathrm{R}_{\mathrm{t}} ; \mathrm{D}_{\mathrm{u}}\right) \\
2^{\mathrm{a}} \text { condição }-\mathrm{Q}_{\mathrm{i}, \mathrm{t}}=\operatorname{menor}\left(\mathrm{R}_{\mathrm{t}}-\mathrm{D}_{\mathrm{u}} ; \mathrm{D}_{\mathrm{i}}\right)
\end{gathered}
$$

Em que:

$\mathrm{Q}_{\mathrm{u}, \mathrm{t}}$ - Vazão urbana atendida no tempo $\mathrm{t}$, em $\mathrm{hm}^{3} / \mathrm{ano}$;

$\mathrm{Q}_{\mathrm{i}, \mathrm{t}}$ - Vazão de irrigação atendida no tempo $\mathrm{t}$, em $\mathrm{hm}^{3} / \mathrm{ano}$;

$\mathrm{R}_{\mathrm{t}}$ - Retirada variável igual ao somatório das vazóes atendidas no ano t, em $\mathrm{hm}^{3} / \mathrm{ano}$;

$\mathrm{D}_{\mathrm{u}}$ - Demanda urbana fixa, em $\mathrm{hm}^{3} / \mathrm{ano}$;

$\mathrm{D}_{\mathrm{i}}$ - Demanda de irrigação fixa, em $\mathrm{hm}^{3} /$ ano.

O rateio linear é o cenário-base deste estudo. A alocação por esse método foi fundamentada na relação existente entre a vazão dos usuários e a vazão disponível para alocação. Assim tem-se:

$$
\begin{aligned}
& \text { Setor urbano }(1-\Delta)=\frac{D_{u}}{R} \\
& \text { Setor de irrigação }(\Delta)=\frac{D_{i}}{R}
\end{aligned}
$$

Os "deltas" representam cenários de alocação sendo utilizados para a análise dos resultados os cenários com os deltas: 0,10, 0,25, 0,50, 0,75 e 0,90.

A vazão alocada por meio do rateio linear pode ser descrita como:

$$
\begin{gathered}
\mathrm{Q}_{\mathrm{u}, \mathrm{t}}=(1-\Delta) * \mathrm{R}_{\mathrm{t}} \\
\mathrm{Q}_{\mathrm{i}, \mathrm{t}}=\Delta * \mathrm{R}_{\mathrm{t}}
\end{gathered}
$$

Em que:

$\mathrm{Q}_{\mathrm{u}, \mathrm{t}}$ - Vazão urbana atendida no tempo $\mathrm{t}$, em $\mathrm{hm}^{3} / \mathrm{ano}$;

$\mathrm{Q}_{\mathrm{i}, \mathrm{t}}$ - Vazão de irrigação atendida no tempo t, em $\mathrm{hm}^{3}$ /ano;

$\mathrm{R}$ - Vazão de retirada em condições ótimas igual à vazão outorgada, em $\mathrm{hm}^{3} / \mathrm{ano}$;

$\mathrm{R}_{\mathrm{t}}$ - Retirada variável igual ao somatório das vazóes atendidas no tempo t, em $\mathrm{hm}^{3} / \mathrm{ano}$;

$\mathrm{D}_{\mathrm{u}}$ - Demanda urbana fixa, em $\mathrm{hm}^{3} /$ ano;

$\mathrm{D}_{\mathrm{i}}$ - Demanda de irrigação fixa, em $\mathrm{hm}^{3} /$ ano.

Assim, definidas as vazóes disponíveis para cada ano t, obtêm-se as vazóes alocadas que cada setor teria considerando as metodologias de alocação. Dessa forma, podem-se verificar as variaçóes de vazóes alocadas em cada setor e seus respectivos impactos aos setores envolvidos.

\section{Avaliação da Transferência de Risco}

A transferência de risco entre os usuários foi avaliada por meio da diferença dos benefícios alcançados por cada setor nos dois métodos de rateio das disponibilidades hídricas, conforme apresentado nas equaçóes a seguir:

$$
\begin{aligned}
& \Delta \mathrm{B}=\mathrm{B}_{\mathrm{k}}^{\mathrm{RL}}-\mathrm{B}_{\mathrm{k}}^{\mathrm{PR}} \\
& \mathrm{TR}=\Delta \mathrm{B}_{\mathrm{u}}-\Delta \mathrm{B}_{\mathrm{i}}
\end{aligned}
$$

Em que:

$\mathrm{B}_{\mathrm{k}}^{\mathrm{RL}}$ é o benefício obtido pelo usuário $\mathrm{k}$ quando foi utilizado o método do rateio linear; 
$\mathrm{B}_{\mathrm{k}}^{\mathrm{PR}}$ representa o benefício obtido pelo usuário $\mathrm{k}$ quando a alocação foi realizada pelo prioridades;

$\mathrm{k}$ corresponde a cada um dos setores usuários de água;

$\Delta \mathrm{B}$ é a diferença de benefícios entre os dois métodos de rateio de disponibilidade hídrica;

TR é o risco transferido.

A diferença de benefício entre os usuários define os recursos financeiros que um setor estaria satisfeito em receber e que o outro setor estaria disposto a desprender. Ou seja, as perdas de um setor e os ganhos do outro setor.

Os benefícios foram calculados através das funçôes propostas por Souza Filho e Brown (2009) que tem como base a elasticidade-preço da demanda. Essas funçóes estáo expostas nas equaçóes 13 e 14:

$$
\begin{gathered}
\mathrm{B}_{\mathrm{i}, \mathrm{t}}=\frac{-0,137 * \mathrm{Q}_{\mathrm{i}, \mathrm{t}}{ }^{2}+79,51 * \mathrm{Q}_{\mathrm{i}, \mathrm{t}}}{1000} \\
\mathrm{~B}_{\mathrm{u}, \mathrm{t}}=\left(-4,75 *\left(\frac{\mathrm{Q}_{\mathrm{u}, \mathrm{t}}}{12}\right)^{-0,818}+2,17\right) * 12
\end{gathered}
$$

Em que:

$\mathrm{B}_{\mathrm{i}, \mathrm{t}}$ representa a função benefício da irrigação em milhôes de reais no tempo $t$;

$\mathrm{B}_{\mathrm{u}, \mathrm{t}}$ designa a função benefício do abastecimento urbano em milhóes de reais no tempo t;

$\mathrm{Q}_{\mathrm{i}, \mathrm{t}}$ corresponde a vazão atendida da irrigação, em $\mathrm{hm}^{3} /$ ano no tempo t;

$\mathrm{Q}_{\mathrm{u}, \mathrm{t}}$ simboliza a vazão atendida do setor de abastecimento urbano, em $\mathrm{hm}^{3}$ /ano no tempo t.

\section{Contrato de Opções}

A arquitetura do contrato de opção deste trabalho tem características semelhantes às aplicadas por Brown e Carriquiry (2007) tendo a liberação total anual como índice do seguro.

As regras contratuais de pactuação entre os setores quando da ocorrência de escassez podem ser concretizadas da seguinte forma:

i) define-se, antecipadamente, o volume do contrato $\left(\mathrm{hm}^{3}\right)$ denominado de "q", por hipótese, esse valor pode ser definido como a razão entre beneficio máximo do cenário e o volume alocável ao setor de irrigação do cenário;

ii) paga-se ao setor de irrigação quando houver transferência hídrica, conforme equação seguinte: $\mathrm{P}(\mathrm{q})=\mathrm{n}^{*} \mathrm{q}$; sendo " $\mathrm{P}(\mathrm{q})$ " a função de pagamentos ao setor transferidor, " $n$ " a quantidade de volume transferido ( $\left.\mathrm{hm}^{3} / \mathrm{ano}\right)$;

iii) o valor anual a ser transferido pelo setor urbano para composição de um fundo financeiro será igual à perda média da série de estudo do setor de irrigação no cenário.

O pagamento das opçôes foi definido conforme as condiçóes a seguir:

Se $Q_{t} \geq S$

Se I $<\mathrm{Q}_{\mathrm{t}}<S \quad \mathrm{P}\left(\mathrm{Q}_{\mathrm{t}}\right)=\mathrm{q} *[\mathrm{I}-(1-\Delta)$

Se $Q_{t} \leq \mathrm{I}$

$$
\mathrm{P}\left(\mathrm{Q}_{\mathrm{t}}\right)=\mathrm{q} * \Delta * \mathrm{Q}_{\mathrm{t}}
$$

Em que $Q_{t}$ denota vazão liberada total no ano t, S e I são os limites de vazão superior e inferior, respectivamente, do contrato.

O limite superior $S$ foi definido pelo somatório da demanda fixa de longo prazo dos dois setores. Enquanto que, o Limite inferior I é a demanda fixa do setor urbano de longo prazo. Em termos matemáticos, têm-se:

$$
\begin{gathered}
S=D_{u}+D_{i} \\
I=D_{u} \\
q=B\left(\bar{Q}_{i, t}\right) / D_{i}
\end{gathered}
$$

Em que $\mathrm{q}=\mathrm{B}\left(\overline{\mathrm{Q}}_{\mathrm{i}, \mathrm{t}}\right) / \mathrm{D}_{\mathrm{i}}$ representa o pagamento máximo definido como benefício de irrigação para sua vazão no ano te q simboliza o coeficiente angular da curva pagamento versus vazão regularizada.

\section{Fundo Financeiro}

O fluxo desse fundo possui as seguintes características: as entradas do fundo seráo baseadas nas perdas e as saídas obedecerão às regras do contrato de opçáo. Já os ganhos foram denominados como as fontes para o pagamento dos prêmios anuais

Quanto a institucionalização e operacionalização desse sistema de gestão de recursos hídricos, pode-se, utilizar-se da estrutura organizacional existente, por exemplo, as entidades responsaveis pela gestão de recursos hídricos locais/regionais.

Assim, a arrecadação da transferência financeira do setor urbano, fonte dos aportes anuais do fundo financeiro, e o pagamento ao setor de irrigação pela 
transferência hídrica pode ser realizada pela companhia de gerenciamento de recurso hídrico.

Para que o setor transferidor realize transferência hídrica, este deve receber algo como contrapartida, por exemplo, recursos financeiros. Já para o setor recebedor, os recursos hídricos transferidos devem corresponder a bônus que pelo menos igualem aos recursos financeiros por este transferidos. Dessa forma, serão apresentados resultados somente dos cenários que atendam as premissas supramencionadas.

Nos cenários que os ganhos superarem as perdas, a diferença entre ganhos e perdas pode ser utilizada para suportar as despesas operacionais do fundo financeiro.

\section{RESULTADOS}

Os sistemas de transferências são análogos aos sistemas de ganhos/perdas, ou seja, para que haja um ganhador deve haver um perdedor. Logo, a variação hídrica e o impacto financeiro do setor urbano são positivos e para o setor de irrigação são negativos.

Examinou-se que a variação dos valores de benefícios dos setores são diferentes, sendo o setor da irrigação mais sensível à transferência hídrica até o delta 0,52 , já o setor urbano torna-se mais sensível a partir do delta igual a 0,66 . Isso pode ser observado nas Figuras 1 e 2 . Observou-se nessas figuras para regióes que a sensibilidade da irrigação é superior à urbana, as perdas superam aos ganhos, e no caso contrário, os ganhos superam as perdas.

Constatou-se que, em apenas na metade dos cenários os impactos financeiros do setor urbano superaram os da irrigação.

Essa constatação pode ser explicada pela diferença de comportamento das curvas de benefícios, principalmente, quanto aos benefícios marginais (Figura 1). Coincidentemente, a partir do ponto que os beneficios marginais do setor urbano supera os da irrigação, os impactos financeiros urbanos superam em valores absolutos os da irrigação.

Entretanto, os resultados apresentados na $\mathrm{Fi}$ gura 3, demonstraram que os ganhos obtidos pela transferência hídrica do setor urbano possuem duas regiôes, a $1^{\text {a }}$ região até a interseção com a curva das perdas, no delta igual a 0,52 , com valores inferiores a estas, considerados cenários inviáveis; e para os deltas maiores que 0,52 , os valores são superiores às perdas,

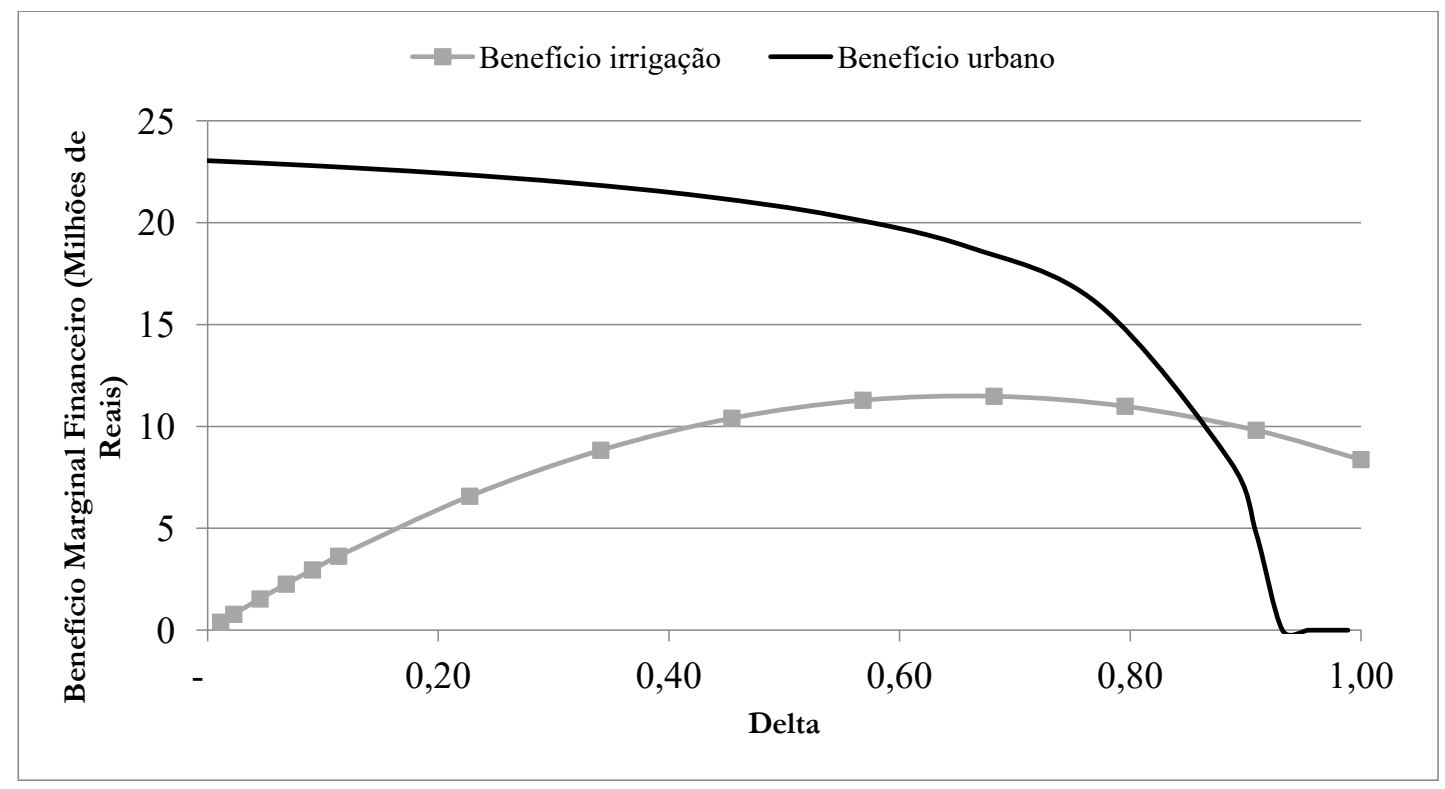

FIGURA 1. Benefícios marginais das equações de benefícios da irrigação e urbano. 
denominado de $2^{\text {a }}$ região, considerados cenários viáveis, sendo, por critérios financeiros, somente estes cenários analisados.

Para esclarecimentos, expóe-se o detalhamento dos resultados na Tabela 1. Nesta tabela percebe que a maior transferência hídrica ocorre próximo ao delta igual a $0,50 \mathrm{com}$ volume médio de 4,96 hm3/ano e com valor médio de "q" igual $\mathrm{R} \$ 49,28\left(10^{3} / \mathrm{hm}^{3}\right)$ gerando um pagamento de opçóes de $\mathrm{R} \$ 244,38$ mil.

No entanto, o maior pagamento de opçóes se dá no delta 0,40 . De outra forma, os pagamentos de opçóes máximos não coincidem com a máxima vazão transferida. Isso ocorreu devido ao comportamento das curvas de vazão média transferida e do valor de "q". Esta possui coeficiente angular negativo constante, aquela, concavidade negativa e assimétrica, ambos em relação ao delta. A combinação desses fatores faz com que o produtório dos pontos dessas curvas também seja assimétrico.

As perdas se comportam de forma semelhante aos pagamentos de opçóes, principalmente quanto ao ponto de máximo. Entretanto, por possuir valores superiores para todo o gráfico, as perdas superam aos pagamentos de opçóes também em todo o gráfico, conforme se pode observar na Figura 3.

TABELA 1

Vazão transferida, valor de " $q$ ", custo da transferência

\begin{tabular}{|c|c|c|c|}
\hline Delta & $\begin{array}{c}\text { Vazão média } \\
\text { transferida } \\
\left(\mathrm{hm}^{3} / \mathrm{ano} \text { ) }\right.\end{array}$ & $\begin{array}{l}\text { Valor de "q" } \\
\left(10^{3} \mathrm{R} \$ / \mathrm{hm}^{3}\right)\end{array}$ & $\begin{array}{c}\text { Pagamento } \\
\text { de opções } \\
\left(10^{3} \mathrm{R} \$\right)\end{array}$ \\
\hline 0,10 & 1,92 & 73,47 & 140,98 \\
\hline 0,25 & 3,98 & 64,40 & 256,46 \\
\hline 0,40 & 4,90 & 55,32 & 271,07 \\
\hline 0,50 & 4,96 & 49,28 & 244,38 \\
\hline 0,52 & 4,94 & 49,27 & 243,39 \\
\hline 0,75 & 3,52 & 34,16 & 120,13 \\
\hline 0,90 & 1,67 & 25,09 & 41,85 \\
\hline
\end{tabular}

A Tabela 2 apresenta os ganhos e as perdas obtidos nas análises. Em relação aos ganhos, constatou-se que estes superam as perdas ou os pagamentos de opçôes

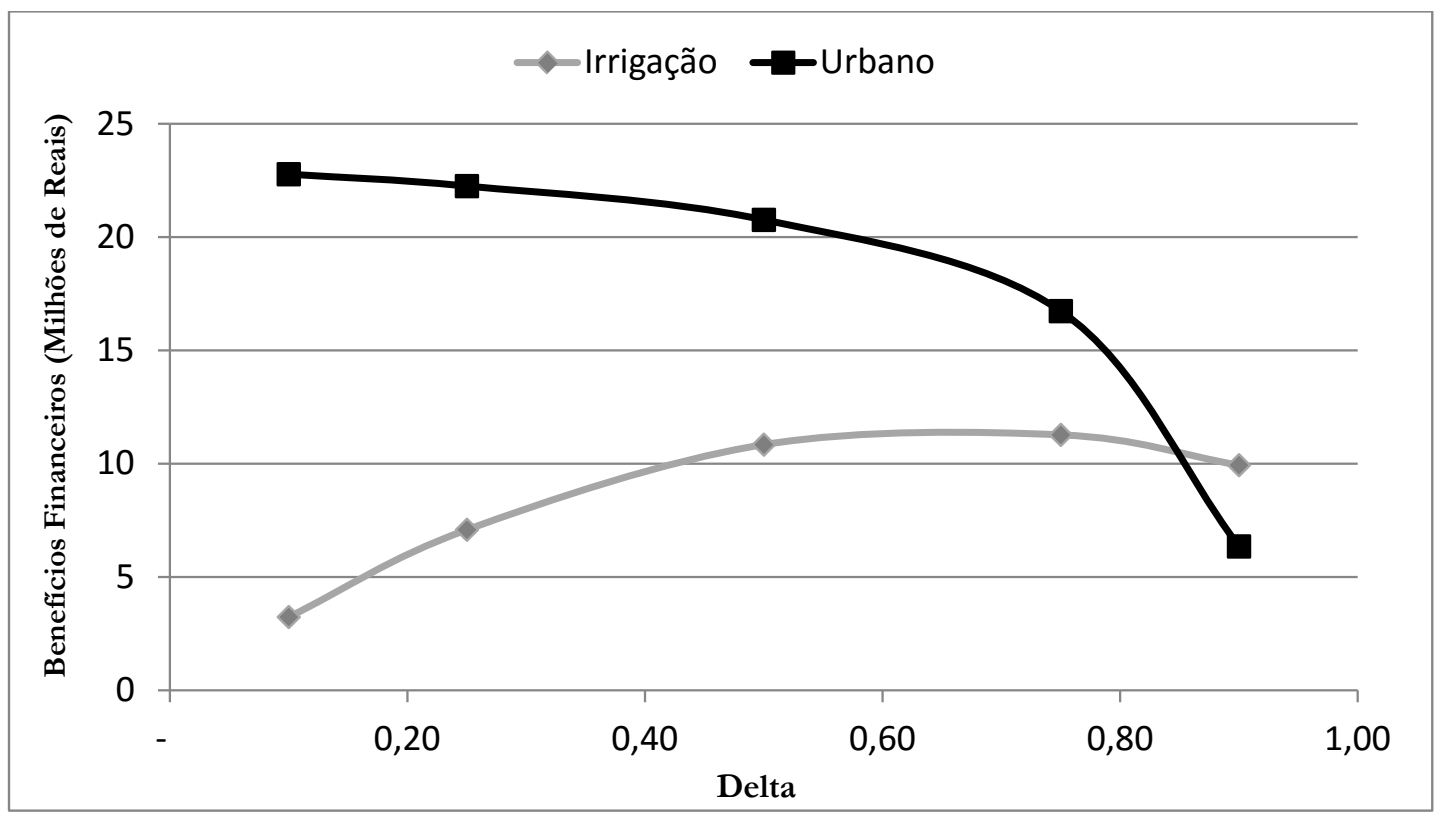

FIGURA 2. Benefícios alcançados pela irrigação e pelo setor urbano (milhões de reais) com a alocação de água. 


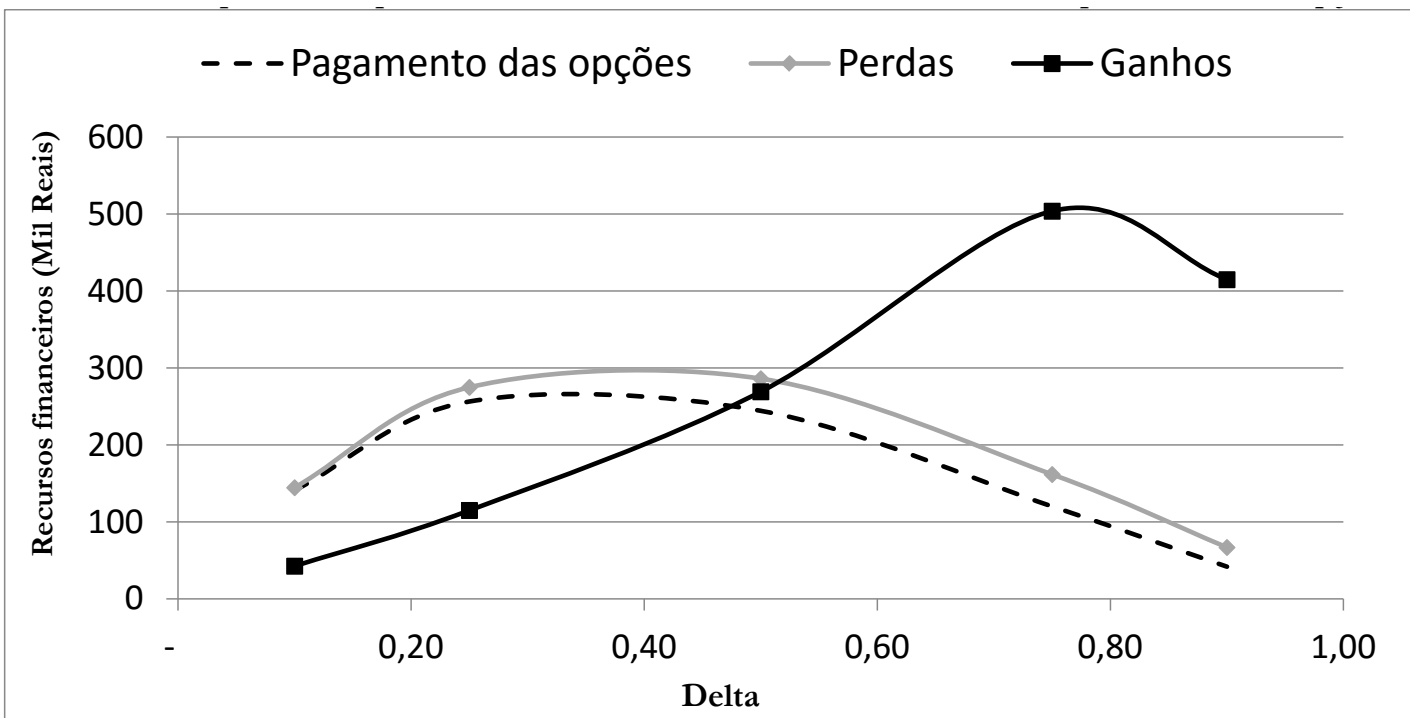

FIGURA 3. Quantificação dos ganhos e das perdas gerados pela aplicação das metodologias de alocação: rateio linear e sistema de prioridades para o reservatório Orós e dos custos da transferência pelo contrato de opção.

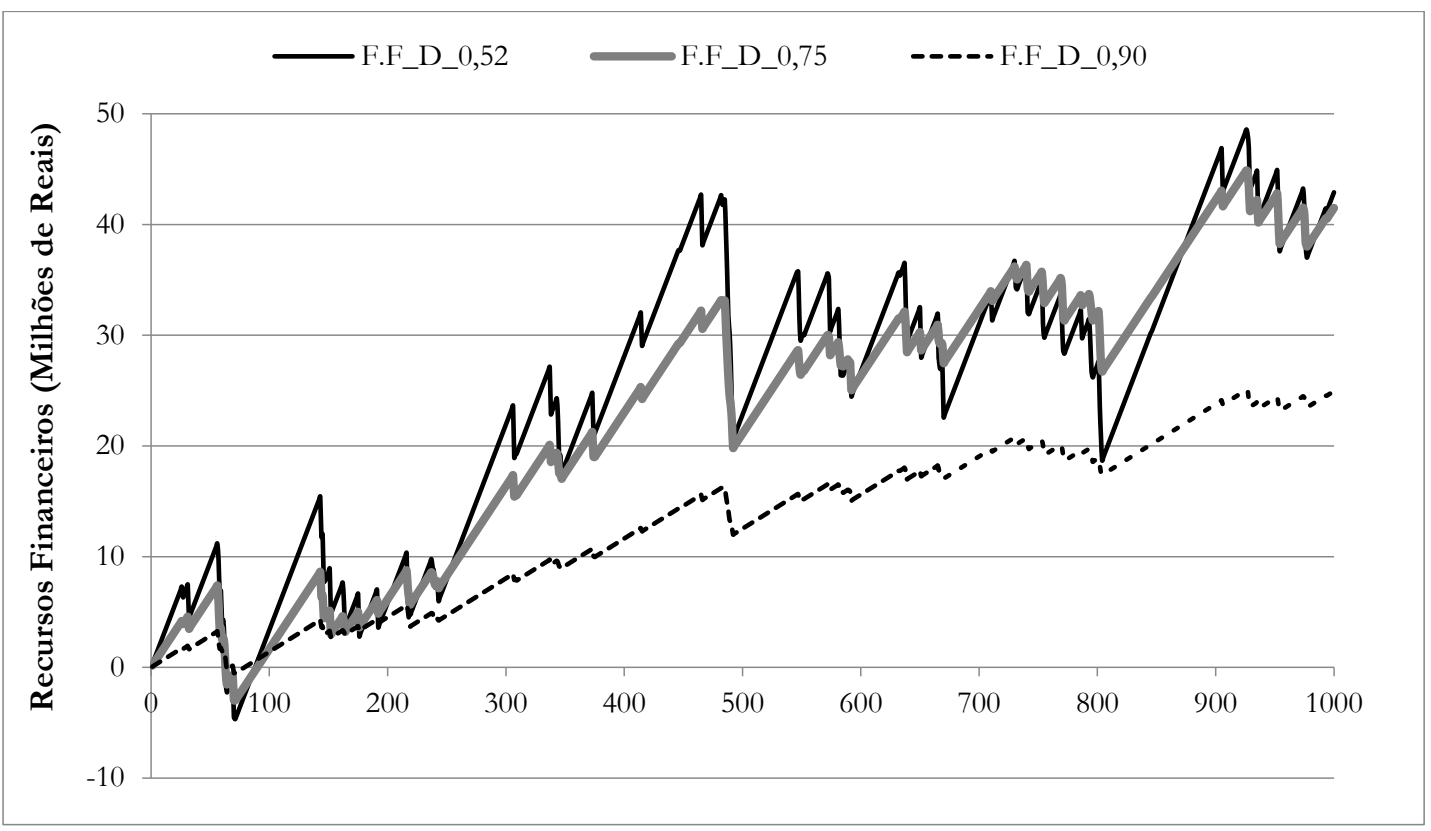

FIGURA 4. Fluxo do fundo financeiro para os cenários 0,52, 0,75 e 0,90. 
após os valores de máximo destes. Contudo, após superá-los, os ganhos crescem de forma mais acelerada e maiores são as diferenças entre ganhos e perdas e entre ganhos e pagamentos de opçóes. A partir do delta 0,52 , os ganhos superam as perdas. Com isso, nesse intervalo (Figura 2) os ganhos podem suportar as despesas financeiras que a operacionalização de fundo financeiro possa exigir.

TABELA 2

Ganhos e perdas para garantia de $90 \%$.

\begin{tabular}{|c|c|c|}
\hline Delta & Ganhos $\left(\mathbf{1 0}^{\mathbf{3}} \mathbf{R} \mathbf{\text { }}\right)$ & Perdas $\left(1 \mathbf{0}^{\mathbf{3}} \mathbf{R} \mathbf{)}\right.$ \\
\hline 0,10 & 42,52 & 144,46 \\
\hline 0,25 & 114,93 & 274,84 \\
\hline 0,40 & 200,66 & 300,09 \\
\hline 0,50 & 269,16 & 286,05 \\
\hline 0,52 & 280,50 & 280,50 \\
\hline 0,75 & 503,79 & 161,62 \\
\hline 0,90 & 414,81 & 66,80 \\
\hline
\end{tabular}

Verificou-se também que quanto maior o delta menor é o recurso hídrico alocado ao setor urbano, ou seja, para grandes deltas, menores as necessidades de recursos hídricos por parte do setor urbano. Todavia, maior será o benefício marginal desse setor e menor o benefício marginal do setor da irrigação.

Contudo, a partir do delta 0,75 , os benefícios marginais do setor urbano diminuem de forma mais acelerada, tornando os benefícios urbanos nulos nos deltas próximos da unidade.

As divergências entre ganhos e perdas advém das diferenças entre os benefícios marginais dos setores envolvidos.

Quanto ao fundo financeiro, ele possui fluxo positivo em quase todo o período, apesar de haver probabilidade de ocorrência de déficits. Esse fato é devido à diferença positiva entre entradas (perdas) e saídas (pagamento de opçóes).

A Tabela 3 apresenta os cenários viáveis para o fluxo financeiro além dos valores dos aporte mínimos para que esse fuxo tenham liquidez em todo o período e que possa suportar as saídas aleatórias elevadas.

Constatou-se a necessidade de maior aporte financeiro no cenário 0,52 , justamente no ponto de igualdade entre perdas e ganhos. Isso deve-se ao fato
TABELA 3

Aportes iniciais mínimos para garantia de $90 \%$

\begin{tabular}{|c|c|c|}
\hline Delta & $\begin{array}{c}\text { Aportes Mínimos } \\
\left(\mathbf{R} \mathbf{\$}^{*} \mathbf{1 0}^{\mathbf{3}} \mathbf{)}\right.\end{array}$ & $\begin{array}{c}\text { Número de aportes } \\
\text { anuais }\end{array}$ \\
\hline 0,52 & 4.682 & 16,70 \\
\hline 0,75 & 2.974 & 18,40 \\
\hline 0,90 & 506 & 7,57 \\
\hline
\end{tabular}

que os maiores impactos econômicos para o setor de irrigação ocorra em torno desse delta devido às maiores probabilidade de transferência de recursos maiores, além de ter menor diferença entre entrada (perdas) e saída (pagamento de opçóes) do fundo financeiro.

O cenário 0,75 possui comportamento semelhante ao do delta 0,52 , tanto em relação ao aporte mínimo quanto ao valor acumulado máximo. Enquanto que, o cenário 0,90 , possui menores valores tanto para o aporte mínimo quanto para o valor acumulado máximo (Figura 4).

Assim, observa-se que para menores deltas, maiores os aportes iniciais necessários e maiores os valores acumulados. Contudo, o número necessário de aportes anuais a fim de superar os déficits podem ser considerados baixos demonstrando que o fundo financeiro seria autossustentável e capaz de cobrir os déficits.

\section{DISCUSSÃO}

Os resultados obtidos a partir da avaliação da transferência de risco entre usuários de água impóem desafios para a gestão de recursos hídricos da região, uma vez que a transferência de água da irrigação para o uso urbano torna-se um mecanismo de racionamento de água.

A redução da garantia hídrica no setor de irrigação pode ocasionar a desestruturação do processo produtivo e do modo de vida das famílias que são dependentes da existência e uso deste para alcançar o desenvolvimento social e econômico. Além disso, conflitos intersetorial e interregional podem ser gerados ou tornar-se mais acirrados.

O contrato de opção firmado entre usuários é uma possibilidade entre outras de promover transferência de risco. Ele tornaria o sistema mais flexível uma vez que este mecanismo seria acionado em períodos secos e desligado em períodos úmidos. Contudo, o 
pagamento das opçôes foi realizado com base nos volumes disponíveis assim, o mecanismo poderia sofrer com o risco moral, isto é, uma açáo oportunista por parte dos usuários.

O fundo financeiro é sustentável e viável em alguns cenários de alocaçáo. Observou-se que quanto menor o delta maior o aporte inicial para que o fundo tenha liquidez mínima e maior será o valor acumulado durante o período de simulação. Além disso, há diferença positivas entre entradas e saídas e os ganhos nessa região podem suportar as despesas financeiras que a operacionalização de fundo financeiro possa exigir.

Ele precisaria ser "blindado" para evitar outros usos além do pagamento das opçōes. Além disso, para operacionaliza-lo seria necessário estudar como inseri-lo no atual sistema de gestão.

Para que os mecanismos propostos funcionem deve-se cobrar de quem possui outorga de uso. Desta forma, deverá ser estudados mecanismos de aprimoramento e integração da outorga com o instrumento de cobrança bem com, a implantaçáo e institucionalização de um sistema de fiscalização e punição para garantir a eficácia do direito de uso e a eficiência do contrato de opçáo.

\section{CONCLUSÃO}

Os impactos financeiros ao setor urbano com base na metodologia de diferença de benefícios apresentaram-se vantajosos apenas para os cenários com valores de deltas intermediários (entre 0,50 e 0,90 ) quando comparados aos impactos do setor de irrigação com base nessa metodologia e nos contratos de opçóes.

Entretanto, a funçáo de pagamentos apresentou-se inviável como metodologia de mensuração de trans- ferência financeira devido aos altos valores para os deltas menores de 0,50 .

Os melhores fluxos dos fundos financeiros, para os casos viáveis, encontram-se no intervalo de deltas entre 0,75 e 0,85 , nos quais os ganhos são significativamente maiores que as perdas ou aos valores dos contratos de opçóes.

A adoção das metodologias de alocação (rateio linear e sistema de prioridades) associadas à metodologia de mensuração econômica dos recursos hídricos por meio das equaçóes de benefícios de cada setor (urbano e irrigação) é adequada à quantificação das transferências hídricas e financeiras, respectivamente.

Além disso, essa metodologia de mensuração econômica associada aos contratos de opçóes com base no seguro baseado no índice "afluência liberada anual" e aos fundos financeiros de recursos hídricos podem ser utilizados pelos gestores dos recursos hídricos como mecanismos de gestão do risco climático em recursos hídricos por possibilitar menores variaçóes nos preços da água e por mitigar os conflitos entre os setores quando da ocorrência de transferência de risco.

A utilização de regras contratuais antes do acontecimento de eventos de escassez hídrica pode ser a melhor ação dos gestores de recursos hídricos a fim de evitar custos abruptos e facilitar as relaçóes entre os setores nesses períodos.

Recomenda-se que trabalhos futuros i) ampliem este estudo para extensão maior do sistema de alocação, ou seja, apliquem em bacias hidrográficas maiores e em sistema mais complexos; ii) estudem os intervalos de deltas que possuem melhores resultados tanto financeiros quanto de pacificação entre os setores envolvidos; e, iii) aprofundem nos estudos de outras variáveis para os contratos de opçóes.

\section{Referências}

BROWN, C.; CARRIQUIRY, M. Managing hydroclimatological risk to water supply with option contracts and reservoir index insurance. Water Res. Research, v. 43, W11423, 2007, doi:10.1029/2007WR006093,

CALIJURI, M. S. S. Avaliação da gestão tributária a partir de uma perspectiva multidisciplinar. 2009. 248 f. Tese (Doutorado), Pós - Graduação em Contabilidade e Controladoria, Universidade de São Paulo, 2009.

CEARÁ. Lei $n^{0}$ 14.844, de 28 de dezembro de 2010. Dispõe sobre a política estadual de recursos hídricos, institui o sistema Integrado de gestão de recursos hídricos - SIGERH, e dá outras providências. 2010.19p.

CHARACKLIS, G. W.; KIRSCH, B. R.; RAMSEY, J.; DILLARD,K. E. M.; KELLEY, C. T. Developing portfolios of water supply transfers. Water Res. Research, v. 42, W05403, doi: 10.1029/2005WR004424, 2006.

MONTANO, P. F. O uso de contratos derivativos como instrumento de gestão de risco na indústria de energia elétrica. 2004. 51f. Monografia (Graduação), Bacharelado em Economia, Universidade Federal do Rio de Janeiro, 2004. 
SKEES, J. R.; COLLIER, B. The Potential of Weather Index Insurance for Spurring a Green Revolution in Africa. Lexington: Global Ag Risk Inc, 2008.

SOUZAFILHO, F. de A; Brown, C. M. (2009), Performance of water policy reforms under scarcity conditions: a case study in Northeast Brazil. Water Policy v. 11, p. 553-568, 2009, doi: 10.2166/wp.2009.141.

UFC/COGERH. Relatório dos Estudos de regionalização de parâmetros de modelo hidrológico chuva-vazão, para as bacias totais e incrementais dos reservatórios monitorados pela Companhia de Gestão dos Recursos Hídricos. Convênio UFC/COGERH/FCPC, Fortaleza, 2013, 24p.

Augusto de Brito Sousa Departamento de Engenharia Hidráulica e Ambiental, Universidade Federal do Ceará, Fortaleza, CE, Brasil. E-mail: absregino@ hotmail.com.

Francisco de Assis de Souza Filho Departamento de Engenharia Hidráulica e Ambiental, Universidade Federal do Ceará, Fortaleza, CE, Brasil. E-mail: assissouzafilho@gmail.com.

Samíria Maria Oliveira da Silva Departamento de Engenharia Hidráulica e Ambiental, Universidade Federal do Ceará, Fortaleza, CE, Brasil. E-mail: samiriamaria@hotmail.com. 